\title{
Manipulatives as Symbols: A New Perspective on the Use of Concrete Objects to Teach Mathematics
}

\author{
DAVID H. UTTAL \\ KATHYRN V. SCUDDER \\ Northwestern University \\ JUDY S. DELOACHE \\ University of Illinois at Urbana Champaign
}

\begin{abstract}
This article offers a new perspective on the use of concrete objects to teach mathematics. It is commonly assumed that concrete manipulatives are effective because they allow children to perform mathematics without understanding arbitrary, written mathematical symbols. We argue that the sharp distinction between concrete and abstract forms of mathematical expression may not be justified. We believe instead that manipulatives are also symbols; teachers intend for them to stand for or represent a concept or written symbol. Consequently, research on how young children comprehend symbolic relations is relevant to studying their comprehension of manipulatives. We review evidence that many of the problems that children encounter when using manipulatives are very similar to problems that they have using other symbol systems such as scale models. Successful use of manipulatives depends on treating them as symbols rather than as substitutes for symbols.
\end{abstract}

A persistent dilemma for teachers of mathematics concerns how to help children understand abstract concepts, such as addition and multiplication, and the symbols that are used to represent these concepts (Hiebert \& Carpenter, 1992; Resnick \& Ford, 1984). Teachers face a double challenge. Symbols may be difficult to teach to children who have not yet grasped the concepts that they represent. At the same time, the concepts may be difficult to teach to children who have not yet mastered the symbols. Not surprisingly, both teachers and mathematics researchers have called for better techniques to help children learn mathematical concepts and symbols.

Direct all correspondence to: David Uttal, Northwestern University, Department of Psychology, 2029 Sheridan Rd, Evanston, IL 60208-2710 < duttal@nwu.ed.>. 
Many of the attempts to improve mathematics instruction have called for greater use of concrete objects. Both teachers and researchers have suggested that concrete objects allow children to establish connections between their everyday experiences and their nascent knowledge of mathematical concepts and symbols. In essence, the assumption has been that concrete objects provide a way around the opaqueness of written mathematical symbols. For example, by dividing a pie or candy for friends, children might acquire an informal understanding of fractions. In the classroom, teachers can then use this initial insight as a base for learning more about fractions and their written representations.

The idea that young children learn best through interacting with concrete objects has sparked much interest in the use of mathematics manipulatives, which are concrete objects that are designed specifically to help children learn mathematics. "Whether termed manipulatives, concrete materials, or concrete objects, physical materials are widely touted as crucial to the improvement of mathematics learning" (Ball, 1992, p. 16). The enthusiasm for manipulatives has reached an almost feverish pitch. For example, Kennedy and Tipps (1994) suggested that "Materials (i.e., manipulatives) make even the most difficult mathematical concepts easier to understand. Manipulatives enable students to connect abstract mathematical concepts to real objects" (p. 71). Tooke, Hyatt, Leigh, Snyder and Borda (1992) claimed that "Mathematics educators around the world have found that mathematics is better learned, and therefore should be taught, by students experiencing it through manipulatives" (p. 61). Manipulatives have been recommended as a means of improving performance for all levels of students, ranging from the developmentally-delayed to the gifted (Peterson, Mercer \& O'Shea, 1988). Moreover, it has been claimed that manipulatives can provide a cure for students' anxiety about mathematics (Martinez, 1987).

Unfortunately, however, research on the effectiveness of manipulatives has failed to demonstrate a clear, consistent advantage for manipulatives over more traditional methods of instruction (Friedman, 1978; Grupe, Huffman \& Bray, 1996; Hiebert \& Carpenter, 1992; Sowell, 1989). Meta-analyses of the literature have shown at best inconsistent and rather limited effects (Sowell, 1989). In addition, several intensive, longitudinal studies of the use of manipulatives in individual classrooms have shown that children do not readily acquire new mathematical concepts from using manipulatives. Extensive instruction and practice may be required before manipulatives become effective (Ball, 1992; Fuson \& Briars, 1990; Resnick \& Omanson, 1987; Wearne \& Hiebert, 1988). In some cases, manipulatives seem to do as much harm as good.

The central thesis of this article is that part of the difficulty that children encounter when using manipulatives stems from the need to interpret the manipulative as a representation of something else. A concrete manipulative may be interesting to young children, but this is not sufficient to advance their knowledge of mathematics or concepts. To learn mathematics from manipulatives, children need to perceive and comprehend relations between the manipulatives and other forms of mathematical expression (Gentner \& Ratterman, 1991). For example, when children solve problems with Dienes blocks, they need to see how operations that are expressed with the blocks can stand for written versions of the same problems (Fuson \& Briars, 1990). Put simply, we do not accept the sharp distinction that has 
been drawn between concrete and symbolic forms of mathematics expression. Instead, we believe that manipulatives, if used successfully, are symbols. To learn from manipulatives, children must comprehend how the manipulative represents a concept or written symbol. Concrete objects can be an effective aid in the mathematics classroom, but to use them effectively, teachers must take into account how children do (or do not) understand symbolic rclations.

For these reasons, we believe that basic research on how children interpret symbols is relevant to understanding and improving the use of manipulatives to teach mathematics. We propose a new perspective on the use of concrete objects in mathematics instruction that is derived from basic research on the development of children's comprehension of symbolic relations.

We are not the only skeptics regarding the effectiveness of the way in which manipulatives are used. Other researchers have also suggested that part of the difficulty that children face in using manipulatives concerns the need to relate them to other forms of mathematical expression (Ball, 1992; Fuson, 1988; Hiebert \& Carpenter, 1992; Resnick \& Omanson, 1987). Nor are we the first to offer a theoretically grounded account of how young children might conceive of relations between objects and concepts (Gentner \& Ratterman, 1991; Sigel, 1993). Our contribution is to clarify the relation between children's comprehension of symbolic relations and their understanding of manipulatives. We also offer a theoretical perspective for thinking about and evaluating the use of manipulatives. We provide empirical evidence that is relevant to manipulative use and that supports our framework. The presentation leads to suggestions regarding the use of manipulatives and the evaluation of their effectiveness.

We begin by sketching briefly the traditional theoretical justification for manipulatives. We then summarize some of our work on children's understanding of models, pictures, and other kinds of symbols. The discussion of these results is followed by a theoretical model, the dual representation hypothesis (DeLoache, 1995), which can account for much of children's success or failure in understanding symbolic relations. We then note important similarities between results regarding children's understanding of symbolic relations and their comprehension of manipulatives.

\section{TRADITIONAL THEORETICAL BASES FOR THE USE OF MANIPULATIVES}

Much of the interest in manipulatives stems from the assumption that the concrete nature of manipulatives makes them particularly appropriate for kindergartners and young elementary school children. In Ball's (1992) words, the assumption has been that "Concrete is inherently good; abstract is inherently not appropriate-at least at the beginning, at least for young learners" (p. 16). The position of the National Council of Teachers of Mathematics (1989) regarding the education of young children is as follows:

Children come to understand number meanings gradually. To encourage these understandings, teachers can offer classroom experiences in which students first manipulate 
physical objects and then use their own language to explain their thinking. This active involvement in, and expressions of, physical manipulations encourages children to reflect on their actions and to construct their own number meanings. In all situations, work with number symbols should be meaningfully linked to concrete materials (p. 38).

The idea that young children learn best through concrete objects is derived, at least in part, from the theories of Piaget (1970), Bruner (1966), and Montessori (1917). From Piaget, educators have adopted the notion that elementary school children's thinking is concrete. It has been assumed that children of this age learn best through concrete objects. Concrete operational children have difficulty performing mental operations on abstract symbols. By this view, making problems tangible also makes them tractable for young children.

Bruner (1966) believed that elementary-school children's thinking focused on concrete properties that could be actively manipulated. Bruner specifically called for the use of concrete objects in instruction, suggesting that using many different concrete objects could help to move children beyond their focus on the perceptual properties of the individual objects. In Bruner's (1966) words, this approach could "empty the concept of specific sensory properties" and allow the student "to grasp its abstract properties" (p. 65).

In sum, educators have concluded that manipulatives are useful because they are concrete and hence do not require children to reason abstractly or symbolically. The assumption is made that experience with particular objects will help children discover the abstract principles such objects embody. In the next section, the results of our research on children's understanding of symbolic relations are presented. These results lead to a very different perspective on the role of concrete objects in young children's thinking.

\section{CHILDREN'S UNDERSTANDING OF SYMBOLIC RELATIONS}

Much of our perspective is derived from the results of research conducted by DeLoache and colleagues (DeLoache, 1987, 1989, 1995) on children's understanding of the relation between a scale model and the room that it represents. At first glance, the work may not seem directly relevant to manipulative use. Much of the research has focused on a single task and has been conducted with children who are substantially younger than those for whom manipulatives typically are designed. However, the results of the work have more general implications that are very relevant to understanding how children may comprehend manipulatives. We therefore review in detail the results of research on children's use of scale models before relating the findings to children's comprehension of manipulatives.

\section{Children's Use of Scale Models}

Much of the research has used a basic paradigm in which children 30 to 38 months of age are asked to use a simple scale model of a room to find a toy that is hidden in the room that the model represents. Both the room and model contain several pieces of furniture, such as a couch, a chair, and a dresser. The individual pieces of furniture in the model are miniatures of the corresponding pieces in the room. 
The task begins with an extensive orientation that is designed to help the child understand that the model represents the room. He or she then witnesses the experimenter hiding the miniature toy in the model behind or under one of the items of furniture. The experimenter tells the child that she has hidden a large toy in the same place in the room. The experimenter and child then enter the room, and the child searches for the toy. This symbol-based retrieval provides critical information about children's understanding of the model-room relation. If they are consistently successful, then children must appreciate how the model and the room are related. After retrieving the large toy, the child returns to the model and retrieves the miniature toy that he or she had seen being hidden. This memory-based retrieval is important because it assesses whether children remember the location of the toy in the model, regardless of whether they find the larger toy in the room. If children succeed on the memory-based retrieval, then difficulties in finding the larger toy in the room cannot be attributed to a failure to remember the location of the toy in the model.

Three aspects of the model task should be emphasized. First, the task involves concrete objects used as symbols: The scale model and the miniature items of furniture within it represent or stand for the room and full-sized furniture. To succeed, children have to detect and exploit the "stands for" relation between the two spaces. Second, although concrete objects and spaces are involved, it is the abstract representational relation between them that is the heart of the task. Detecting the lower level object similarities between corresponding full-sized and miniature objects is not sufficient for success (DeLoache, 1995). Third, although the model task involves retrieving toys in physical spaces in which objects are arrayed in corresponding spatial configurations, it is children's representation of the "stands for" relation between the two spaces that is necessary for successful performance.

The scale model task is thus like the use of manipulatives in that both involve concrete objects as symbols and abstract "stands for" relations between those objects and other entities. Thus, factors that make it easier or more difficult to use a model as a representation may similarly affect the use of manipulatives. At the same time, models and manipulatives differ in various ways, including the fact that the model represents another concrete entity-a room-whereas manipulatives represent abstract concepts and operations. Nevertheless, the need in both cases to detect and use a symbolic relation suggests that insights gained from the study of young children's understanding and use of scale models may illuminate older children's understanding and use of manipulatives.

Children Often Have Difficulty Gaining Insight into the Relation between the Model and the Room. To an adult, the model task seems trivial. The model and the room look so much alike that one might believe that the relation between the two could be directly perceived. Yet 2.5-year-olds had great difficulty using the model as a symbol of the room. They almost always failed the symbol-based retrievals, averaging around $20 \%$ correct searches. In contrast, children only six months older were quite successful, averaging around $80 \%$ correct searches (DeLoache, 1987). Both groups, however, were very good at the memory-based retrievals. Thus, the young children's difficulty was not due to a failure to remember the location of the toy in the model. Instead, the younger children failed to appreciate the relation between the model and the room and that this relation was relevant 
to finding the toy. The younger children did not grasp this seemingly simple and apparently transparent symbolic relation.

It is interesting to note that the 2.5-year-olds apparently kept track of what was going on in both spaces. In the room, they simply guessed where to look on the first symbol-based retrieval, but on subsequent trials, they frequently searched wherever they had found the toy on the preceding trial in the room. In the model, their high success on the memory-based retrieval shows they kept track of where they had initially observed the toy being hidden. Thus, the 2.5-year-olds searched systematically in both spaces (albeit more correctly in the model). They treated both as meaningful and real, yet independent, situations. In some sense, the younger children, who were unaware of the model-room relation, were doing more mental work than the older children. The older children had only to remember the location of one toy and transfer that memory representation to the other space, whereas the younger children were maintaining and acting on the basis of two separate memory representations.

Children's Comprehension of the Model-Room Relation Depends on Instruction. Subsequent research revealed that despite their excellent performance in the initial studies, 3-year-olds' understanding of the relation between the model and the room was quite fragile. What appeared to be trivial manipulations caused 3-year-olds' performance to fall to the low levels typical of 2.5-year-olds.

For example, instructions proved to be a key factor. If the initial orientation and instructions about the relation between the model and the room were deleted, 3-year-olds' performance fell to chance levels (DeLoache, 1989). Without instructions, the 3-year-olds performed comparably to the 2.5-year-olds in the original studies. Young children need to be told exactly how the model and room are related; they do not spontaneously perceive the relation between them.

Children May Easily Lose Sight of the Model-Room Relation. Even when children do gain insight into the relation between the model and the room, they easily forget that this relation can help them find the toy in the room. A recent set of studies (Uttal, Schreiber \& DeLoache, 1995) demonstrated that having to wait to use the model-room relation dramatically lowers 3-year-olds' performance. In these experiments, the model, room, and instructions were the same as those of the studies in which 3-year-olds typically succeed. The only difference was that children were not allowed to search for the toy in the room immediately after witnessing the hiding of the miniature toy in the model. Instead, they had to wait either 20 -sec, 2 -min or 5-min on the first trial. On the subsequent trials, the children experienced different delays, in counterbalanced order. For example, the group that experienced the 5-min delay first (i.e., the long-delay-first group) then experienced the $20 \mathrm{sec}$ delay on the second trial.

The initial delay had a drastic effect on children's performance. In particular, the long-delay-first group (5-min delay on the first trial) failed to retrieve the toy, not only on that trial but throughout -even on the subsequent trials that involved shorter delays. These children could not even find the toy on the 20 -sec delay trials. In contrast, children who 
experienced the short $(20-\mathrm{sec})$ delay on the first trial performed reasonably well throughout, even on some of the 5-min delay trials.

Why was the initial 5-min delay so devastating? We believe that during the initial delay, the children lost sight of the relation between the model and the room. They no longer saw the model as relevant and hence they searched in the room without regard for the location of the toy in the model. They conceived of the task as two separate, unrelated searches: one for the miniature toy in the model, and one for the larger toy in the room (Uttal et al., 1995). Thus, even when young children have an initial understanding of a symbol-referent (modelroom) relation, they can easily lose track of that relation.

Explaining Children's Performance-the Dual Representation Hypothesis. Why is a child's comprehension of the model-room relation so tenuous? The dual-representation hypothesis provides a theoretical account of the difficulties that children experience in attempting to use symbolic relations. The core principle of the dual-representation hypothesis is that a scale model (or any concrete symbol) can be thought of in two different ways: (a) as an object in its own right and (b) as a representation of something else (i.e., the room). One can think of the these two construals of the model as sitting on opposite sides of a balance scale. Factors that tip the balance toward attending to the model as an object may simultaneously decrease the likelihood of thinking of the model as a symbol. Conversely, factors that tip that balance in the opposite direction, away from thinking of the model as an object, increase the likelihood that children will be able to exploit the model as a symbol for the room.

The dual-representation hypothesis helps to explain both success and failure in the model task. The model is an attractive, interesting object in its own right. Children's interest in the model thus tips the balance toward focusing on it as an object and away from perceiving it as a representation of the room. With specific instructions and other supports, such as a high degree of similarity between the model and the room (DeLoache, Kolstad \& Anderson, 1991), the balance can be tipped toward children thinking of the model as a symbol. Similarly, prior experience in using a model can help children succeed on other model tasks that they would normally fail (Marzolf \& DeLoache, 1994). These and other manipulations help children to think of the model as a representation of the room.

Our account of children's performance leads to several interesting and counterintuitive predictions. For example, it suggests that making the model more interesting or salient as an object may decrease children's use of the model as a symbol. Conversely, the dualrepresentation hypothesis predicts that making the model less interesting or salient as an object in its own right may increase performance. Both of these predictions have been confirmed. In one study, children were allowed to play with the model for 5 to $10 \mathrm{~min}$ before they were asked to use it as a symbol (DeLoache, 1995). These children performed worse than children who had never seen the model before. Presumably, playing with the model beforehand led children to think of it as an object. They consequently had more difficulty thinking of the model as a representation of the room. On the other hand, a second study showed that decreasing the salience of the model as an object increased children's ability to treat it as a symbol. In this study, the model was placed behind a window. Children therefore 
could observe the toy being hidden in the model, but they never touched or otherwise experienced the model directly. Placing the model behind glass decreased its attractiveness as an interesting object and hence allowed children to construe it as a representation of the room.

The strongest test of the dual-representation hypothesis to date is a series of experiments in which the need to think of the model as a representation of the room was eliminated (DeLoache, 1995). This was done by convincing 2.5 year-old children that a machine could shrink the room (into the model). First, the children saw a toy troll placed in front of the "shrinking machine" (an oscilloscope). After a brief interval spent in a nearby room, the children returned to find a miniature troll in its place. Next, the experimenter demonstrated that the machine could also shrink the room (a tent-like portable room used in many other studies). The machine was pointed at the room, and the child and experimenter again waited in the nearby area. When they returned, the model was sitting in the area previously occupied by the portable room. For the crucial test trials, the child watched as the troll doll was hidden in the room, waited while the machine "shrunk" the room and the toy, and then searched for the toy.

Two things are noteworthy about this task: First, the children were asked to do exactly the same thing as in the model task-find one toy based on where they saw the other toy hidden in the other space. Second, the basis for doing so was different. If the children believe the shrinking machine scenario, then to them, the model was the room. There was no representational relation between the two spaces and hence no need for dual representation. As predicted, the children successfully retrieved the toy when they thought the room and model were one and the same. This result provides strong support for the concept of dual representation and vividly illustrates the particular difficulty young children can have with symbolic relations. In sum, dual representation is an important factor in children's use of the model as a symbol of the room. We believe that the dual representation concept is relevant to understanding children's comprehension of many other types of symbols, including manipulatives. In the next section, we discuss some of the common problems children encounter when using models and manipulatives.

\section{RELEVANCE TO MANIPULATIVES}

There are two general implications of the dual-representation hypothesis that are particularly relevant to children's use of manipulatives. First, our previous results and the dualrepresentation hypothesis leads us to suggest that the relation between manipulatives and their intended referents may not be transparent to children. We find it hard to think of a symbol and referent that could be more alike than the model and the room, yet detecting this seemingly transparent relation can be extremely hard for young children. If young children have so much difficulty comprehending such a simple relation, then older children may have difficulty comprehending less transparent relations, such as those between manipulatives and the concepts they are designed to represent. 
The second general implication of our work is that concreteness does not necessarily confer an advantage in terms of young children's comprehension of symbol-referent relations. According to the dual-representation hypothesis, it is the concreteness of the model that makes it difficult to use as a symbol. Making symbols concrete and interesting as objects in themselves may decrease the chances of a child treating them as representations.

In sum, the dual representation hypothesis suggests that to use any object, including a mathematics manipulative, as a symbolic representation, children must appreciate the relation between the object and its referent. Whether manipulatives are effective teaching tools depends upon whether children interpret them as representations of something else and understand the nature of the representational relation.

\section{Children Often Have Difficulty Gaining Insight into the Relation between a Manipulative and the Concept that it is Intended to Represent}

The ultimate goal of using manipulatives is to help children grasp abstract concepts and the written symbols that are used to represent these concepts. However, there is no guarantee that children will establish the necessary connections between manipulatives and more traditional mathematical expressions (Bruner, 1966; Fuson \& Briars, 1990; Hiebert \& Carpenter, 1992; Resnick \& Omanson, 1987). Although children may learn to perform mathematical operations with manipulatives, they often fail to link this knowledge to more traditional forms of mathematical expression. As our research on young children's understanding of symbolic relations demonstrates, the process of establishing a connection between a symbol and its referent is not simple.

Dramatic evidence for the difficulty that children face in establishing connections between manipulatives and mathematical concepts or symbols comes from a series of studies conducted by Resnick and Omanson (1987). This research addressed whether and how third graders established connections between different forms of mathematical expression (e.g., counting Dienes blocks and understanding basic concepts in subtraction, such as borrowing tens). Resnick and Omanson studied the development of children's comprehension of mathematical information as expressed both in manipulatives and in more standard, written forms. For example, children were asked to express addition and subtraction problems with Dienes blocks and then to write the same problems.

Children's progress in both domains was evaluated over the course of the school year. Most children showed progress in using the Dienes blocks and other manipulatives. They had acquired, for example, an understanding of the relations between the different units of blocks (ones, tens, hundreds, etc.) Most children could interpret the Dienes blocks expressions for numbers involving hundreds, tens, and ones. Moreover, they could solve multidigit addition and subtraction problems with the blocks.

Unfortunately, children's success with the manipulatives did not convey an advantage when they were asked to interpret written expressions of problems that were conceptually similar to the block problems. A child who could solve a problem such as $103+52$ with blocks might still have great difficulty solving written problems, such as $12+14$, that were ostensibly simpler than the blocks problems. Solutions involving Dienes blocks appeared to be separated in children's minds from written solutions. Indeed, the child who performed 
the best with the Dienes blocks performed the worst in the written subtraction problems. Despite mastering Dienes blocks expressions and solutions for many subtraction problems, the same children continued to demonstrate only a formulaic, perfunctory approach to written problems. This approach led to many buggy algorithms in which children persistently applied incorrect strategies to written problems, regardless of whether they could solve the problems with manipulatives. Solving problems with Dienes blocks may have helped children learn more about mathematics, but this new knowledge appeared to remain tacit and seemingly unrelated to information presented in class or in textbooks. Put simply, the children often failed to perceive how the Dienes blocks represented other forms of mathematical expression.

Resnick and Omanson's (1987) results demonstrate that the link between traditional, written problems and those involving manipulatives may be tenuous or nonexistent in the minds of elementary school children. Another example demonstrates that children may have difficulty thinking. of manipulatives specifically as alternate representations of mathematical concepts. Hughes (1986) asked 5- to 7-year-olds to solve simple problems, such as $1+7=$ 8 , with toy bricks. The children were told to use the bricks to show the written problems. Thus, children were asked to translate the abstract, symbolic representation of the written problem into a concrete representation with the bricks.

On average, children's performance was poor; they had difficulty using the bricks to represent the written problems. More importantly, their errors reveal a possible source of the difficulty. Many of the children took the instructions literally and used the bricks simply to copy the written problems (see Figure 1). They did not understand that the bricks were intended to represent a mathematical concept. Just as children in our model task often do not comprehend the model-room relation, the participants in Hughes' study did not understand that the bricks were not simply objects and that they could be used to represent the numbers.

One final example of the difficulty that students encounter with concrete objects comes from a more advanced level of instruction, high school geometry. In many classes, teachers use constructions with the intent of helping children gain insight into geometrical principles or the logic of proofs. Students may be asked, for example, to cut or fold paper to form a particular shape, with the constraint that they may use only a straight edge and a compass. Although geometric constructions are not the same as the manipulatives typically used in elementary school classrooms, there is an important similarity: Both manipulatives and constructions are concrete objects that are intended to help students gain insight into more abstract mathematics concepts and written symbols.

Just as younger children have trouble establishing connections between manipulatives and mathematics concepts and symbols, older children have difficulty making a connection between geometric constructions and proofs. Students often fail to realize that the constructions and proofs are intended to teach a similar concept. Consequently, even when students complete a particular construction, they may continue to fail problems or proofs that are conceptually very similar to the construction. Schoenfeld (1986) described students' understanding of the relation between proofs and concrete objects such as those used in constructions: 


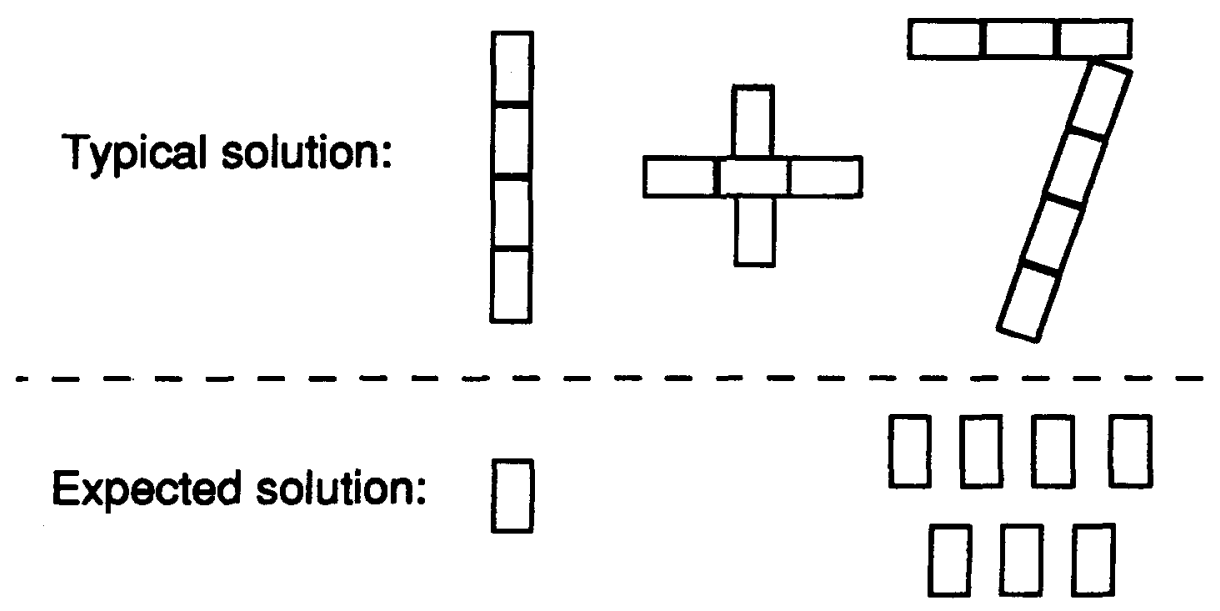

FIC. 1. A hypothetical example of children's use of blocks to represent arithmetic problems. Children might copy the bricks as shown in the top portion of the figure. The solution that a teacher would expect is shown in the bottom portion of the figure. (Adapted from Hughes, 1986.)

...a fair number of students ignored the results they had derived in the proof problems, making conjectures that flatly contradicted what they had just proved. ...the students simply did not see any connection between the deductive mathematics of theorem proving and the inductive mathematics of doing constructions (p. 243).

Schoenfeld's observations seem consistent with the frustrations that many students and parents experience with high school geometry. Two of the authors have struggled with teachers' demands to produce a construction that satisfies some ill-specified geometric criteria, but that is also creative and neatly executed. As we diligently tried to meet the teachers' expectations, we and our children wondered what the construction had to do with geometry. The construction took on a life of its own, one that had little or nothing to do with the concepts that the teacher had introduced in class. Although we cannot speak for all students or parents, we have a strong suspicion that the frustrating evenings spent working on such constructions are a common experience in the homes of many high school students. Once again, we see that focusing on objects decreases the chances of students perceiving how the objects relate to what the teacher intends for students to learn.

In sum, these examples illustrate a key point: If children do not connect the manipulatives they are required to use with the relevant concepts they are required to learn, then they are forced to do double duty. They must learn two separate systems. Like the younger children who kept track of hiding places in the scale model and the room independently, such students would labor under an increased cognitive load. Thus, using manipulatives in a classroom without insuring that students fully understand their relation to the mathematical concepts being taught might be counter-productive. For one thing, the time and effort spent mastering the manipulatives would be time and effort not devoted to learning the concepts in the first 
place. For another, the juxtaposition of two systems that children are learning separately might be confusing and impede their progress in the target system-mathematics.

\section{Children May Lose Sight of the Relation between Manipulatives and Their Intended Referents}

Another implication of our research on children's use of models is that even when children initially grasp the relation between the manipulative and other forms of mathematics expression, their understanding can be quite tenuous and is easily lost. Recall that delays dramatically affected children's use of the model as a symbol of the room (Uttal et al., 1995). Inserting a 5-min delay between the hiding of the toy in the model and children's search in the room caused children to lose sight of the model-room relation and of the relevance of this relation for finding the toy in the room.

We believe a similar problem may arise when children are asked to use concrete objects to solve mathematics problems. Even if children understand initially that the manipulative is related to the problem or to a written representation of the problem, there is no guarantee that they will retain this understanding. This may be particularly true when children learn something with a manipulative and then are asked to apply this knowledge on a different day (Resnick \& Omanson, 1987).

\section{Children's Comprehension of Manipulatives Depends on Instruction}

Manipulatives are often viewed as a tool for self-guided instruction; the assumption has been that children can learn mathematics directly by playing with or acting upon the manipulatives (Ball, 1992). However, we believe that children are unlikely to directly perceive the relation between manipulatives and abstract mathematical symbols (Fuson, 1988). Instead, their comprehension of these relations needs to be guided and constrained by teachers' instructions, just as children's comprehension of the model-room relation depends upon instruction.

An important characteristic of programs that successfully use manipulatives is that instruction and manipulative use are linked from the outset. Consider, for example, Wearne and Hiebert's (1988) description of a successful instruction program that incorporates manipulatives. The focus of their program was fractions, but their results could apply to many other domains of mathematics instruction. The goal of the program was to help children understand abstract, written expressions of the fractions.

The first and perhaps most important step was connecting. "This process is the construction of links between individual symbols (i.e., written mathematical expressions) and familiar referents. . . Connections must be established for both numerical symbols and operation symbols." (Wearne \& Hiebert, 1988, p. 372). These connections often involve manipulatives, such as Dienes blocks or money. Rather than presenting manipulatives first and then the written mathematical symbols, the two forms of expression are linked from the outset. The manipulatives are used as a bridge to help children master the abstract, written fractions, but it is never assumed that children will make this connection on their own. The entire program is aimed at helping children gain insight into the relation between the various forms in which fractions can be expressed. 
Another example of the importance of instructions is Fuson and Briars' (1990) approach to using base-ten blocks to help children understand multidigit subtraction and addition. The program incorporates explicit and repeated linkages by the teacher between the mathematics concepts that are expressed in blocks and in written form. As in Wearne and Hiebert's program, concrete and written expressions are pointed out from the beginning, and each step with the blocks is immediately recorded with the written marks. In addition, teachers continuously monitor children's comprehension to ensure that children do not separate knowledge gained through the use of blocks from the corresponding written expression.

\section{Manipulatives and the Dual Representation Hypothesis}

We believe that many of the problems that children encounter when using manipulatives can be explained in terms of dual representation. Recall that we explained much of young children's behavior in our model studies in terms of whether children appreciated the model both as a symbol of the room and as an interesting object. A similar theoretical account can be applied to children's use of manipulatives. Children must conceive of a manipulative as a representation of a mathematics concept at the same time that they treat it as an object. Our review of some of the problems that students encounter when using manipulatives suggests that they often fail to think of the manipulative as a representation of something else. They treat such objects as distinct entities that are unrelated to what the teacher might intend for them to learn. Students may learn to perform mathematical operations with the manipulatives, but too often this knowledge is seen as relevant only to the manipulatives themselves. The key problem appears to be a failure to conceive of the manipulative as a representation of something other than itself.

As in our research on children's use of models, the dual-representation hypothesis leads to counterintuitive suggestions and predictions. For example, one implication concerns the choice of manipulatives. Many educators assume that manipulatives should be attractive, interesting objects that engage children's attention. Moreover, it has been assumed that using many different manipulatives in close succession should facilitate children's learning (Ball, 1992; Bruner, 1966). These assumptions may be derived in part from Bruner's theory, which suggested that "multiple embodiments" of a mathematical concept helped children grasp the underlying concept without focusing on any single form or expression of the concept. For example, by completing addition problems with blocks, rods, tiles, and so forth, children presumably would learn about addition rather than how to add blocks or how to add rods.

We believe, however, that using highly attractive and different kinds of objects as manipulatives may actually have the opposite effect: Children may focus more on the manipulatives as objects per se rather than on the relation of the objects to a concept or an alternate form of expression. Our research with scale models revealed that highlighting the characteristics of the model as a thing in itself hindered children's comprehension of it as a symbol of the room (DeLoache, 1995). Highly attractive objects may not make good symbols precisely because they are interesting as objects. Langer (1951) made this point long ago, suggesting that a peach would not make a good symbol because people care too much about peaches. The same may hold true for manipulatives. Highly interesting and attractive objects may not make good manipulatives because children care too much about the objects 
themselves. Using many different kinds of bright, beautiful manipulatives may push children's attention toward the objects themselves and away from where it needs to be-on the relation of the symbol to what the children are supposed to learn.

The idea that manipulatives should be entertaining or otherwise appealing is not shared by all educators. For example, in Japan, children begin first grade with a small manipulative set that includes blocks and other shapes. The same manipulative set is used throughout the lower elementary grades. We would expect that the manipulatives become highly familiar and hence less interesting as objects in their own right. Becoming accustomed to the same manipulative set might free the children to focus instead on what the manipulatives represent (Uttal et al., in press). Support for this claim comes from Sowell's (1989) meta-analysis, which revealed that manipulatives were most effective when they were used consistently over extended periods of time.

In the United States, however, teachers place great emphasis on the use of many different objects in many different situations. Stevenson and Stigler (1992) have observed:

Japanese teachers... use the items in the math set repeatedly throughout the elementary school years.... American teachers seek variety. They may use Popsicle sticks in one lesson, and marbles, Cheerios, M\&M's, checkers, poker chips, or plastic animals in another. The American view is that objects should be varied in order to maintain children's interest. The Asian view is that using a variety of representational materials may confuse children, and thereby make it more difficult for them to use the objects for the representation and solution of mathematics problems. Multiplication is easier to understand when the same tiles are used as were used when the children learned to add (pp. 186-187).

\section{IMPLICATIONS}

We believe that this article raises several important questions and issues for manipulative use in everyday mathematics classes.

1. Manipulatives are not a panacea. The most general implication of our analysis concerns the common assumption that concrete objects are an inherently good way to teach young children mathematics. As discussed above, manipulatives do not offer a magical advantage to the mathematics teacher. The use of concrete objects in mathematics instruction can be effective, but the concreteness of the objects does not, in itself, hold the key for unlocking the mysteries of mathematics. In Ball's (1992) words, "understanding does not travel through the fingertips and up the arm.... Mathematical ideas really do not reside in cardboard and plastic materials" (p. 47). Regardless of whether manipulatives are used, learning mathematics must always involve mastering symbolic relations. Young children may not perceive the relation of manipulatives to underlying, core principles of mathematics unless these relations are specifically highlighted.

2. Teachers must consider children's interpretation of manipulatives. It is a truism to suggest that teachers need to take children's perspectives into account. Yet, to adults, the 
relation between some symbols and their referents is so transparent that it is difficult to conceive of children failing to comprehend the relation. For example, despite over a decade of work with scale models, we are still sometimes shocked when an intelligent and interested 3 -year-old fails to appreciate the relation between the model and the room. To adults, the relation is completely transparent, but to young children, the relation can be surprisingly opaque. We believe a similar problem may arise when manipulatives are used in the classroom. To the teacher, the relation between the manipulative and what he or she intends for it to represent seems simple and transparent. But this is rarely the case. A prudent assumption may be that children will fail to establish a connection between manipulatives and other symbols or concepts unless the connection is pointed out explicitly and repeatedly.

3. Manipulatives cannot be a substitute for instruction. To use manipulatives successfully, teachers must link instructions with children's nascent conceptions of what the manipulatives represent. Manipulatives may help children to discover mathematical concepts, but this knowledge is likely to remain encapsulated as a set of principles and procedures that children think of only in terms of a particular manipulative. In other words, without instruction, children may treat manipulatives as interesting objects that have little or no connection to anything else. The common assumption that manipulatives allow children to discover mathematical principles on their own should not be taken to mean that children do not need instructions about the relation of manipulatives to other forms of expression.

4. Manipulatives must be chosen and used carefully. Some kinds of manipulatives are more likely to be effective than others. Our analysis leads to two suggestions regarding the choice of manipulatives and their use in classrooms:

First, a good manipulative should facilitate, rather than hinder, children's perception of the relation between the manipulative and what the teacher hopes the children will learn. In this regard, objects that are particularly interesting or attractive may make particularly bad manipulatives. Similarly, the common use of items that children already know about as objects (e.g., toys, food, etc.) may interfere with a child's comprehension of the symbolic nature of the manipulative. It is possible that the best manipulatives will be objects that are not used for anything other than mathematics instruction. The objects that compose the set should be privileged, in that they are intended to serve only as manipulatives. Children would then learn not to focus on the objects themselves. Instead, they would come to expect that the teacher is using the objects to illustrate a new concept or written symbol.

Second, our analysis suggests that some kinds of manipulatives may be more effective than others in terms of helping children gain insight into the underlying mathematical concepts. Young children are much more successful when the model and room are perceptually similar (DeLoache, Kolstadt \& Anderson, 1991). By analogy, we believe that manipulative systems, such as Dienes Blocks, that have an internal structure that is systematically related to the concepts they represent may help children to focus on the relation between the manipulative and its intended referent. Dienes blocks are systematically related to their intended referent in that specific block units (e.g., ones, tens, hundreds) correspond 
to significant units in the base-ten number system (Fuson \& Briars, 1990). Perhaps this is one reason why programs that report successful use of manipulative systems have often used Dienes blocks.

\section{FUTURE DIRECTIONS}

The goal of this paper has been to raise issues regarding the general value of concreteness and the effectiveness of manipulatives in math education. We have relied heavily on comparison and analogies between previous work on young children's understanding of scale models and older children's use of manipulatives. We have assumed that the difficulties older children encounter with manipulatives may have the same origin as the difficulties young children encounter in the model task. Both may be attributable in part to problems comprehending and using concrete objects as representations of something else.

The issues raised regarding the use of manipulatives in math education could be directly addressed by testing predictions derived from the scale model research and particularly the dual-representation hypothesis. For example, one clear prediction is that simpler, less inherently interesting objects would be more useful as symbols than more complex, interesting objects. Another is that children's use of manipulatives should be improved by explicit instructions and reminders of the representational nature of those objects. If a better understanding is achieved of the problems children have linking manipulatives with the concepts they represent, then the efficacy of such objects for educational purposes should be greatly enhanced.

\section{CONCLUSION}

The initial promise of manipulatives was that they could link mathematics concepts with objects and processes that were already familiar to young children. The hope was that manipulatives would make mathematics more accessible for young children. Consequently, students would find mathematics intrinsically interesting and would be able to establish meaningful connections between written mathematics symbols and the concepts that they represent.

Despite our criticisms of the use of manipulatives, we believe that the assumptions about the value of manipulatives may still be true. Concrete objects can help children gain access to concepts and processes that might otherwise remain inaccessible. However, there is another side to the use of concrete objects: children may easily fail to appreciate that the manipulative is intended to represent something else-that it is a symbol. If so, the manipulative will be counterproductive. By considering the difficulties that children encounter when attempting to use any symbol system, teachers will be able to foresee and perhaps eliminate many of the problems that have interfered with the effective use of manipulatives in the past. To be effective, attempts at educational reform must take into account how children perceive symbolic relations. 
This article has focused on mathematics instruction, but the perspective may also be relevant to other domains, such as reading instruction. Consider, for example, one of the episodes from Sesame Street, a beauty pageant for letters. The letters stroll down the runway dressed in beautiful evening gowns and bedecked with jewelry. The master of ceremonies crowns and then sings in honor of the winner, a song that names the many words beginning with the lucky letter. Most parents and educators would agree that episodes such as these are interesting and engaging for children (and their parents!). But what would preschoolers take away from the episode? Parents and teachers hope that children learn something about the letters that was relevant to reading. However, our perspective on concrete objects leads us to think twice about the value of having letters come to life. Children may become so interested in the properties of the letters as interesting objects that they lose sight of the relation between letters, sounds, and words. When concrete objects are used as symbols, it is important to strike a balance between keeping children's interest in the object and helping them focus on the relevance of the object as a symbol. One of the most important accomplishments of preschool and elementary education is mastering a variety of symbol systems. Mastering these symbol systems can be a difficult task. Manipulatives can be effective when they are used to facilitate, rather than obscure, the process of learning about symbolic relations.

Acknowledgment Portions of this work were funded by research Grant HD-25271 and training Grant HD-07205 from the National Institute for Child Health and Human Development. The work was also supported by Grant MH54504-01 from the National Institute of Mental Health. Portions were presented at the 1994 meeting of the Jean Piaget Society, Chicago. We thank Theresa Graham, Dedre Gentner, Vanessa Gregg, and Harold Stevenson for their helpful suggestions.

\section{REFERENCES}

Ball, D.L. (1992). Magical hopes: Manipulatives and the reform of math education. American Educator, 16, 14-18. Bruner, J.S. (1966). Toward a theory of instruction. Cambridge, MA: Belknap Press.

DeLoache, J.S. (1987). Rapid change in the symbolic functioning of very young children. Science, 238(4833), 1556-1557.

- (1989). Young children's understanding of the correspondence between a scale model and a larger space. Cognitive Development, 4(2), 121-139.

-. (1995). Early symbol understanding and use. In D. Medin(Ed.), The psychology of learning and motivation, Vol. 33 (pp. 65-114). New York: Academic Press.

DeLoache, J.S., Kolstad, V. \& Anderson, K. (1991). Physical similarity and young children's understanding of scale models. Child Development, 62, 111-126.

Friedman, M. (1978). The manipulative materials strategy: The latest pied piper? Journal for Research in Mathematics Education, 9, 78-80.

Fuson, K.C. (1988). Children's counting and concepts of number. New York: Springer-Verlag.

Fuson, K.C. \& Briars, D.J. (1990). Using a base-ten blocks learning/teaching approach for first and second grade place-value and multidigit addition and subtraction. Journal for Research in Mathematics Education, 21, $180-206$. 
Gentner, D. \& Ratterman, M.J. (1991). Language and the career of similarity. In S.A. Gelman \& J.P. Byrnes (Eds.), Perspectives on thought and language: Interrelations in development, (pp. 225-277). London: Cambridge University Press.

Grupe, L.A., Huffman, L.F. \& Bray, N.W. (1996). Addition strategies in kindergarten children. Paper presented at the Conference on Human Development, Birmingham, AL.

Hiebert, J. \& Carpenter, T.P. (1992). Learning and teaching with understanding. In D. A. Grouws (Ed.), Handbook of research on mathematics teaching and learning, (pp. 65-97). New York: Macmillan.

Hughes, M. (1986). Children and number: Difficulties in learning mathematics. Oxford: Basil Blackwell.

Kennedy, L.M. \& Tipps, S. (1994). Guiding children 's learning of mathematics, 7th ed. Belmont, CA: Wadsworth. Langer, S.K.K. (1951). Philosophy in a new key. Cambridge, MA: Harvard University Press.

Martinez, J.G.R. (1987). Preventing math anxiety: A prescription. Academic Therapy, 23, 117-125.

Marzolf, D. \& DeLoache, J.S. (1994). Transfer in young children's understanding of spatial representations. Child Development, 65, 1-15.

Montessori, M. (1917). The advanced Montessori method. New York: Frederick A. Stokes.

National Council of Teachers of Mathematics. (1989). Curriculum and evaluation standards for school mathematics.

Peterson, S.K., Mercer, C.D. \& O'Shea, L. (1988). Teaching learning disabled students place value using the concrete to abstract sequence. Learning Disabilities Research, 4, 52-56.

Piaget, J. (1970). Science of education and the psychology of the child (D. Coltman, Trans.). New York: Orion Press.

Resnick, L.B. \& Ford, W.W. (1984). The psychology of mathematics for instruction. Hillsdale, NJ: Erlbaum.

Resnick, L.B. \& Omanson, S.F. (1987). Learning to understand arithmetic. In R. Glaser (Ed.), Advances in instructional psychology, Vol. 3 (pp. 41-96). Hillsdale, NJ: Erlbaum.

Schoenfeld, A.H. (1986). On having and using geometric knowledge. In J. Hiebert (Ed.), Conceptual and procedural knowledge: The case of mathematics (pp. 225-264).

Hillsdale, NJ: Erlbaum.

Sigel, I.E. (1993). The centrality of a distancing model for the development of representational competence. In R. R. Cocking \& K. A. Rennigner (Eds.), The development and meaning of psychological distance (pp. 141-158). Hillsdale, NJ: Erlbaum.

Sowell, E.J. (1989). Effects of manipulative materials in mathematics instruction. Journal for Research in Mathematics Education, 20(5), 498-505.

Stevenson, H.W. \& Stigler, J.W. (1992). The learning gap: Why our schools are failing and what we can learn from Japanese and Chinese education. New York: Summit Books.

Tooke, D.J., Hyatt, B., Leigh, M., Snyder, B. \& Borda, T. (1992). Why aren't manipulatives used in every middle school mathematics classroom? Middle School Journal, 24, 61-62.

Uttal, D., Schreiber, J.C. \& DeLoache, J.S. (1995). Waiting to use a symbol: The effects of delay on children's use of models. Child Development, 66, 1875-1891.

Uttal, D.H., Marzolf, D.P., Pierroutsakos, S.L., Smith, C.M., Troseth, G.L., Scudder, K.V. \& DeLoache, J.S. (in press). Seeing through symbols? The development of children's understanding of symbolic relations. In B. Spodek \& O.N. Saracho (Eds.), Play in early childhood education. Albany: State University of New York Press.

Wearne, D. \& Hiebert, J. (1988). A cognitive approach to meaningful mathematics instruction: Testing a local theory using decimal numbers. Journal for Research in Mathematics Education, 19, 371-384. 